$\underline{\mathbf{P}-70}$

\title{
Extractives from Eusideroxylon Zwageri and Potoxylon Melagangai Against white-Rot Fungi
}

\author{
Faiezah Abdullah ${ }^{1,3, *}$ Ismail Jusoh ${ }^{2}$ and Zaini Assim ${ }^{3}$
}

${ }^{I}$ Pusat Asasi, Universiti Teknologi MARA, 42300 Bandar Puncak Alam, Malaysia; ${ }^{2}$ Department of Plant Science and Environmental Ecology, Faculty of Resource Science and Technology, Universiti Malaysia Sarawak, 94300 Kota Samarahan, Malaysia; ${ }^{3}$ Department of Chemistry, Faculty of Resource Science and Technology, Universiti Malaysia Sarawak, 94300 Kota Samarahan, Malaysia; E-mail: faiezah2892@puncakalam.uitm.edu.my

Belian (Eusideroxylon zwageri) and Malagangai (Potoxylon melagangai) are two of the most durable timbers in Malaysia. The durability of the timbers is influenced by their extractives constituents. The heartwood of both woods was extracted using acetone by Soxhlet. The crude extracts were sub-sequentially fractionated using solvent of increasing polarity. Acetone extracts were then exposed to two white-rot fungi, namely Pycnoporus coccineus and Schizophyllum commune. The extractives removed by acetone were $11.66 \%$ and $12.26 \%$ from $E$. zwageri and $P$. melagangai woods, respectively. The acetone extracts of E. zwageri was reduced to $7.95 \%$ and $4.46 \%$ after exposure to $P$. coccineus and $S$. commune, respectively. For $P$. melagangai acetone extracts reduced to $4.84 \%$ and $2.77 \%$ after exposure to the same fungi. $P$. coccineus was found to degrade wood extractives more efficiently compare to $S$. commune. Among common compounds found from fractionated extractives were 5 octadecene, palmitic acid and 4-tetradecanol while compounds highly degraded were 9-octadecene, 4-tetradecanol and 2propenoic acid. Vanillin, 1-nitro-3,5-dimethoxyphenyl-ethylene, 2,4-dimethoxy-5,6-dimethylbenzaldehyde, benzenamine and 5-allyl-1,2,3-trimethoxybenzene compounds derived after wood exposure to both fungi. Cytotoxicity test against brine-shrimp, Artemia salina indicated that the extractives were toxic. $\mathrm{LC}_{50}$ of acetone crude extracts of E. zwageri and P. melagangai were obtained at $0.8 \mu \mathrm{g} / \mathrm{ml}$ and $56.2 \mu \mathrm{g} / \mathrm{ml}$, respectively.

Keywords: Eusideroxylon zwageri, Potoxylon melagangai, extractives, white-rot fungi. 